Document downloaded from:

http://hdl.handle.net/10251/145990

This paper must be cited as:

Felismino, CDJ.; Helal-Neto, E.; Portilho, F.; Rocha Pinto, S.; Sancenón Galarza, F.; Martínez-Máñez, R.; Ferreira, ADA.... (10-0). Effect of obesity on biodistribution of nanoparticles. Journal of Controlled Release. 281:11-18.

https://doi.org/10.1016/j.jconrel.2018.05.003

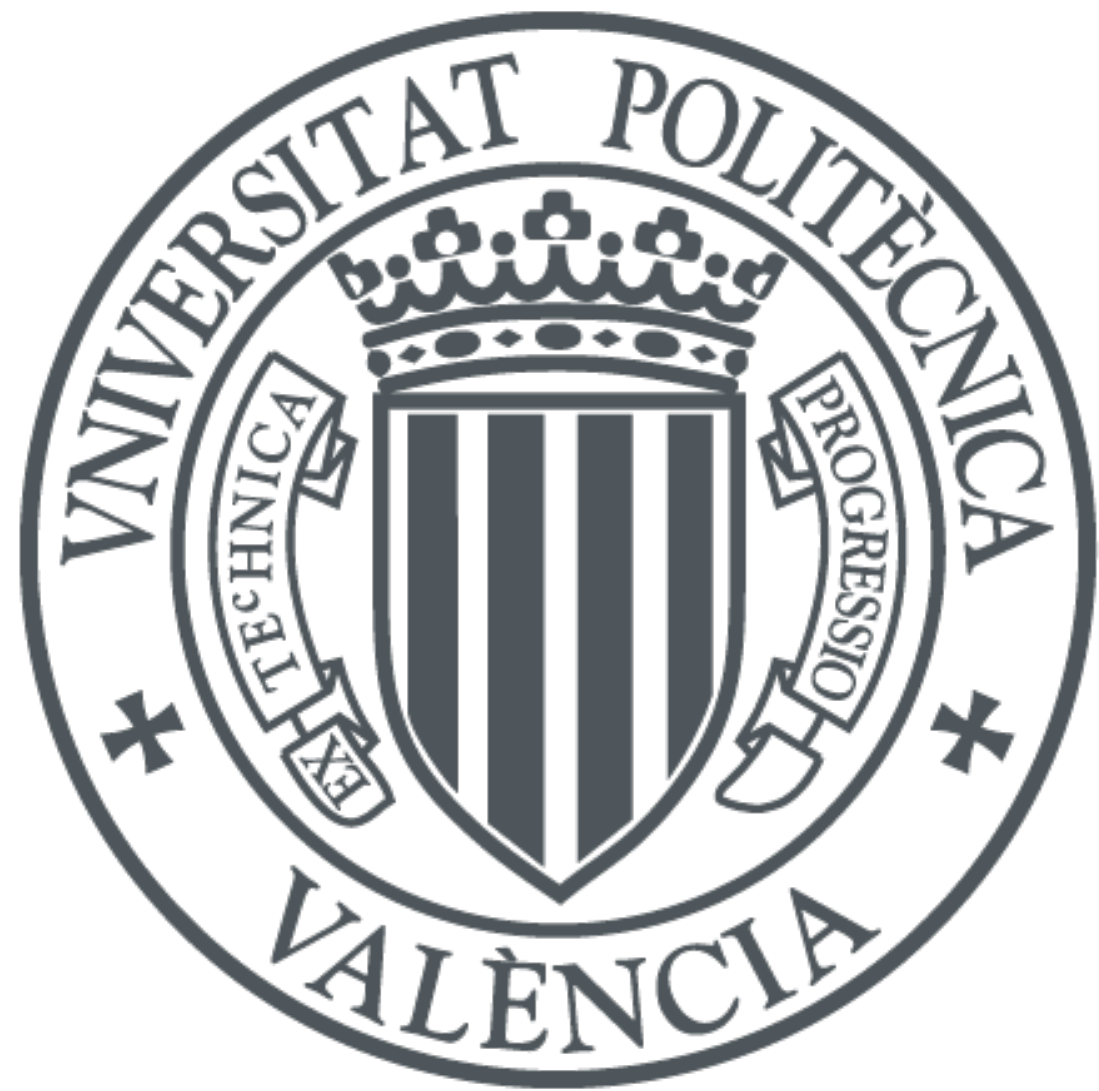

The final publication is available at

https://doi.org/10.1016/j.jconrel.2018.05.003

Copyright Elsevier

Additional Information 


\section{Effect of Obesity on Biodistribution ofNanoparticles}

Claudiana de Jesus Felismino ${ }^{1}$, Edward Helal-Neto ${ }^{1}$, Filipe Leal Portilho ${ }^{1}$, Suyene Rocha Pinto ${ }^{1}$, Félix Sancenón ${ }^{2,3,4}$, Ramón Martínez-Máñez ${ }^{2,3,4}$, Agatha de Assis Ferreira $^{5}$, Simone Vargas da Silva ${ }^{5}$, Thereza Christina Barja-Fidalgo ${ }^{5}$, Ralph Santos-Oliveira ${ }^{1,6}$

1- Brazilian Nuclear Energy Commission, Nuclear Engineering Institute, Rio de Janeiro, Brazil

2- Instituto Interuniversitario de Investigación de Reconocimiento Molecular y Desarrollo Tecnológico (IDM), UniversitatPolitècnica de València, Universitat de València. Caminode Vera s/n, 46022, Valencia, Spain

3- Departamento de Química, Universidad Politécnica de Valencia, Caminode Vera s/n, 46022, Valencia, Spain.

4- CIBER de Bioingeniería, Biomateriales y Nanomedicina (CIBER-BBN).

5- LaboratoryofCellularand Molecular Pharmacology; DepartmentofCellBiology, IBRAG, Universidade do Estado do Rio de Janeiro,RJ, Brazil

6- Laboratory of Radiopharmacy and Nanoradiopharmaceuticals, Zona Oeste State University, Rio de Janeiro, Brazil

\section{All correspondence to}

Dr Ralph Santos-Oliveira

Laboratory of Radiopharmacy and Nanoradiopharmaceuticals roliveira@ien.gov.br 
Graphical Abstract

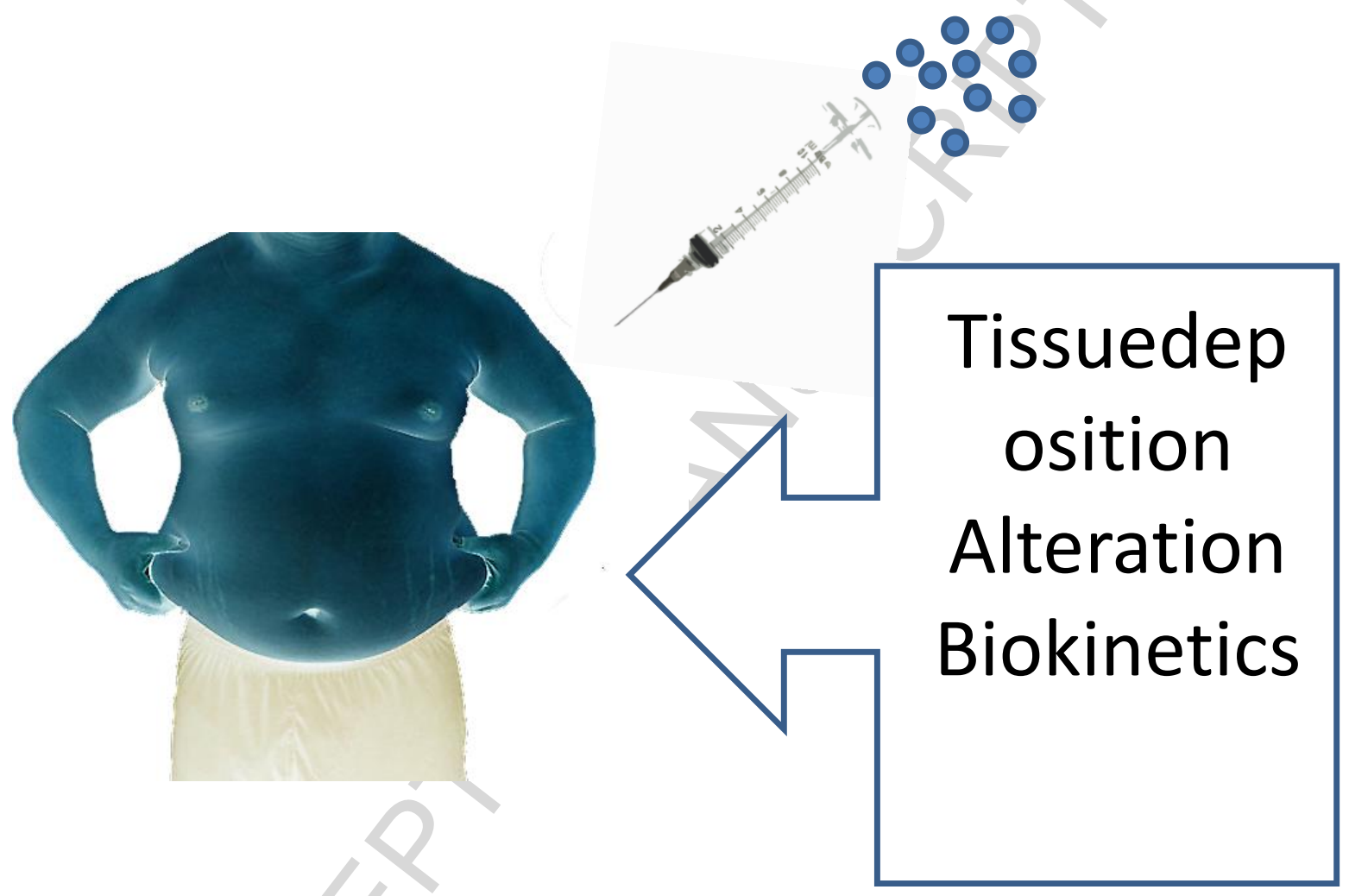




\section{ABSTRACT}

Nanoparticles have specific features (lipophilicity, surface charge, composition and size). Studies regarding the biological behavior of nanoparticles in diseases such diabetics and obesity are scarce. Here, we evaluated two nanoparticles: magnetic core mesoporous silica (MSN) $(58 \mathrm{~nm})$ and polycaprolactone $(\mathrm{PCL})$ nanoparticle $(280 \mathrm{~nm})$ in obese mice. Changes in the biodistribution were observed, especially considering the mononuclear phagocyte system (MPS), and the visceral fat tissue. Nonetheless, our data corroborates the influence of size in the biodistribution in obese animals, supporting that smaller nanoparticles, may show a higher tissue deposition at spleen, due the associated splenomegaly and the complications arising from this state. Finally, our study demonstrated that, in obesity, probably due the low-grade inflammatory state associated with metabolic syndrome a difference in accumulation of nanoparticles wasfound, with profound impact in the tissue deposition of nanoparticles.

Key words: obesity; nanoparticle; tissue deposition; metabolic alteration; biodistribution 


\section{INTRODUCTION}

Overweight and obesity can be defined as an accumulation of abnormal or excessive body fat, which can be harmful to health. In accordance to the World Health Organization (WHO) the number of obese people in the world more than doubled since the 1980s, and is considered, since 1975 as a chronic disease ${ }^{[1]}$. Also, obesity has a strong link with several co-morbidities, especially the type 2 diabetes mellitus ${ }^{[2]}$.

The increased content of fat, in contrast to a low percentage of lean tissue and water, besides several physiopathological modifications often associated to obesity, may affect drugbiodistributionand elimination. In these individuals, the blood flows per gram of fat is lower than in nonobese, and histological hepatic alterations are usually associated to markedly alteration in the RES (Reticuloendothelial System). Furthermore, obese patients present a higher glomerular filtration rate and, consequently, a differentiated volume of distribution, with serious implication in loading-dose parameter ${ }^{[2-6]}$.

In general, the use of nanoparticles associated with cosmetic formulations and as drug itself is increasing globally. Accordingly the FDA (Food and Drug Administration) approved over $350^{[7]}$ nanodrugs that are already available in market, among them liposomes are the most commonly used nanostructures, followed by nanocrystals and over 7.000 nano-based products were commercialized in the last years. Because of the physicochemical properties that make the nanomaterials suitable for bio tagging or targeting, different approaches using nanodrugs have been attempt for the treatment of obesity ${ }^{[8]}$. 
Since the use of nanodrugs is rapidly increasing worldwide, more information must be acquired, especially at specific strata of the population as obese. In this scenario we evaluated the biodistribution and tissue deposition of two nanomaterials: i) magnetic core mesoporous silica and ii) polymeric nanoparticles, in order to understand the changes caused by the obesity. The choice of these two systems was based on the structural differences between both, especially size, surface area and physicochemical properties.

\section{MATERIALS AND METHODS}

\section{Preparation of Magnetic Core Mesoporous Silica Nanoparticles} Reagents and Materials

Iron (III) chloride hexahydrate, iron (II) tetrachloride hexahydrate, oleic acid, hexadecyltrimethylammonium bromide (CTAB) and tetraethyl orthosilicate (TEOS) were purchased form Sigma. Ammonia solution (32\%), ethanol and ethyl acetate were purchased from Scharlau. Chloroform was obtained from Acros Organics. Distilled water was used in all reactions.

\section{Synthesis of oleate-coated iron oxide nanoparticles}

Iron oxide nanoparticles $\left(\mathrm{Fe}_{3} \mathrm{O}_{4}\right.$ magnetite nanocrystals) were obtained by a modified coprecipiationmethod $^{[9]}$. Briefly, $12 \mathrm{~g}$ of iron (III) chloride hexahydrate were mixed with $4.9 \mathrm{~g}$ of iron (II) chloride tetrahydrate in $50 \mathrm{ml}$ of water at $80{ }^{\circ} \mathrm{C}$ under a flow of argon and mechanical stirring. Ammonia solution 32\% (19.53 ml) 
was carefully added and the mixture turned completely dark. Oleic acid $(2.13 \mathrm{ml})$ was added after $30 \mathrm{~min}$ and the reaction was left stirring at $80 \stackrel{\circ}{\circ}$ for another 90 $\min$. The reaction was cooled down and centrifuged at $9500 \mathrm{rpm}$ during $10 \mathrm{~min}$. The resulting black precipitate was washed three times with distilled water and three times with ethanol and then dried under vacuum overnight. In order to prevent their oxidation, the oleate-coated iron oxide nanoparticles were kept in chloroform giving a dark brown ferrofluid.

\section{Synthesis of magnetic core MSNs}

In a typical procedure, $100 \mathrm{mg}$ of CTAB were dissolved in $10 \mathrm{ml}$ of water, followed by addition of $0.74 \mathrm{ml}$ of the ferrofluid $(8.88 \mathrm{mg} / \mathrm{ml})$. The mixture was placed in a probe sonicator (Branson 450 Sonifier) for 2 min, giving an oil-in-water emulsion. Then, the mixture was heated to $65^{\circ} \mathrm{C}$ to evaporate the chloroform and achieve an effective phase transfer from chloroform to water. The resulting transparent aqueous suspension was added to a solution of $30 \mathrm{ml}$ of water and $0.548 \mathrm{ml}$ of ammonia (32\%), which was then, heated up to $75^{\circ} \mathrm{C}$. Then, $0.5 \mathrm{ml}$ of tetraethyl orthosilicate (TEOS) was added dropwise followed by addition of $3 \mathrm{ml}$ of ethyl acetate. The reaction was stirred at $350 \mathrm{rpm}$ and $75 \stackrel{\circ}{\circ} \mathrm{C}$ during $3 \mathrm{~h}$. Then, the reaction was placed on an ice bath and the nanoparticles were collected by centrifugation (9500 rpm, $10 \mathrm{~min}$ ). Afterward, the sample was washed with ethanol twice and dried under vacuum overnight. The final magnetic core MSNs were calcined in air at $550^{\circ} \mathrm{C}$ for $5 \mathrm{~h}$. 


\section{Characterization of magnetic core MSNs}

\section{Powder X-ray Diffraction}

The synthesised materials were characterised by powder X-ray diffraction (PXRD), transmission electron microscopy (TEM) and $\mathrm{N}_{2}$ adsorption-desorption analysis. PXRD measurements were obtained using a Bruker AXS D8 Advance diffractometer equipped with CuKa radiation and working at $40 \mathrm{kV} / 40 \mathrm{~mA}$. PXRD measurements were performed at high angle $\left(2 \theta=15^{\circ}-68^{\circ}\right)$ and low angle range $\left(2 \theta=1.3^{\circ}-8.3^{\circ}\right)$.

\section{Transmission Electron Microscopy}

TEM images were taken on a $100 \mathrm{kV}$ JEOL JEM-1010 microscope operated with AMT image capture engine software. TEM samples were prepared by adding $10 \mu \mathrm{l}$ of nanoparticles suspended in distilled water onto carbon-coated copper grids. The statistical analysis of the data obtained from TEM images was performed using Origin Pro software.

\section{$\mathrm{N}_{2}$ adsorption-desorption}

$\mathrm{N}_{2}$ adsorption-desorption measurements were conducted in a TriStar II Plus surface area and porosity analyzer from Micromeritics. The specific surface area of the material was determined from the adsorption-desorption isotherm by applying the BET model. The pore volume and average pore size was estimated by using the BJH model.

\section{Ethambutol Polymeric Nanoparticle}




\section{Development of Ethambutol Nanoparticle}

To the nanoparticles preparation, an ethambutol tablet $(400 \mathrm{mg}$ of ethambutol hydrochloride, oral administration) was triturated and then an amount containing $5 \mathrm{mg}$ of ethambutol was weighted (which represents $10 \%$ of the polymer mass to be added to the nanoparticle) and solubilized in 0.1 wt\% PVA aqueous solution.

Ethambutol nanoparticles were preparedby double emulsion solvent evaporation method where $200 \mu \mathrm{L}$ of ethambutol-PVA aqueous solution was dripped into $2 \mathrm{~mL}$ of dichloromethane, where $50 \mathrm{mg}$ of PCL (with a molar mass of $42000 \mathrm{~g} / \mathrm{mol}$ ) were previously solubilized and then sonicated (UP100H, Hielscher) for 1 minute at $55 \mathrm{~W}$ to produce a water-in-oil emulsion. This emulsion was emulsified again with $4 \mathrm{~mL}$ of PVA 1 wt\% solution by ultrasound processing for 2 $\min (55 \mathrm{~W})$ to produce a $\mathrm{W} / \mathrm{O} / \mathrm{W}$ emulsion.

Then dichloromethane was evaporated under reduced pressure during 1 hour at $25^{\circ} \mathrm{C}$. PCL-NPs were recovered by centrifugation $(20,000 \mathrm{rpm}$ for $20 \mathrm{~min})$ and washed twice with distilled water to remove the excess of PVA. At the end only PCL- ethambutol nanoparticles were used.

\section{Size determination by DLS}

Nanoparticles size distribution, mean size and polydispersity index (PDI) of the ethambutol nanoparticle were determined by dynamic light scattering (DLS) using the equipment Zetasizer Nano ZS (Malvern Instruments, UK). Measurements were performed in triplicate at $25^{\circ} \mathrm{C}$ and the laser incidence angle in relation to the 
sample was $173^{\circ}$ using a $12 \mathrm{~mm}^{2}$ quartz cuvette. The mean \pm standard deviation (SD) was assessed.

\section{Scanning Electron Microscopy (SEM)}

The morphology of nanoparticles was examined by Scanning Electron Microscopy (SEM) (TM 3000 - Hitachi), with a tension varying from 10 to $20 \mathrm{kV}$. The sample, $10 \mu \mathrm{L}$ of the nanoparticle solution, was fixed on a carbon tape and dried under aseptic conditions.

\section{Labeling Process with ${ }^{99 \mathrm{~m}} \mathrm{Tc}$}

The labeling process was done by the direct radiolabeling process as described previously [10,11]. In this methodology we used $150 \mu \mathrm{g}$ of each nanoparticle: i) Magnetic Core Mesoporous Silica Nanoparticles, ii) ethambutol polymeric nanoparticle. Briefly, $100 \mu \mathrm{Ci}$ (approximately $300 \mu \mathrm{L}$ ) of ${ }^{99 \mathrm{~m}} \mathrm{Tc}$ was incubated with a stannous chloride $\left(\mathrm{SnCl}_{2}\right)$ solutions $(80 \mu \mathrm{g} / \mathrm{mL})$ (Sigma-Aldrich) for 20 minutes at room temperature. Then this solution was incubated with $150 \mu \mathrm{g}$ of each nanoparticle (Magnetic Core Mesoporous Silica Nanoparticles and Ethambutol Polymeric Nanoparticles) for another 10 minutes in order to label their structures.

\section{Quality Control of the Labeling Process with 99mTc}

In order to confirm the efficacy of the labeling process with the nanoparticles was performed a paper chromatography using Whatman paper $n^{\circ} 1$. In this direction was used $2 \mu \mathrm{l}$ of the labeled-nanoparticle and acetone (Sigma-Aldrich) as 
mobile phase. The radioactivity of the strips was verified in a $\mathrm{y}$-counter (Perkin Elmer Wizard® 2470, Shelton, CT City, State).

\section{In vivo Analysis}

\section{Animals and high fat diet (HFD) protocol}

All experiments on animals were conducted according to the principles of NIH Guide for the Care and Use of Laboratory Animals and were approved by the Committee for the Ethics of Animal Experimentation of the Universidade do Estado do Rio de Janeiro (Permit number: CEA/024/2017).

Male C57BL/6 mice $(n=12)$ were obtained from Federal University of Rio de Janeiro (UFRJ, Rio de Janeiro, Brazil) at 3 weeks of age. After 1 week of adaptation, the animals were housed separate cages and were fed either regular chow (C; $396 \mathrm{Kcal} / 100 \mathrm{~g}, 13 \%$ of energy derived from fat) or a High Fat Diet (HFD, $470 \mathrm{Kcal} / 100 \mathrm{~g}, 45 \%$ of energy derived from fat) for 10 weeks in a temperature-controlled room $\left(25 \pm 1^{\circ} \mathrm{C}\right)$, with $60 \%$ humidity and 12 -hours artificial light-dark cycle. Body weight was measured throughout the treatment period.

\section{Body composition analysis}

Body composition analysis was performed by nuclear magnetic resonance. Briefly, mice were scanned using the body composition analyzer for small animals (Bruker's Minispec LF90 TD-NMR, Massachusetts, USA). The instrument was calibrated for these studies using NMR scans and chemical composition data from 10 mice (body weight range 25 - 40 g.) On day of testing, a quality control check 
of internal voltages, temperature, magnets, and NMR parameters was performed using a standard provided by the manufacturer. Animals were placed in a clear, plastic cylinder (50 mm diameter) and kept immobile by insertion of a tight fitting plunger into the cylinder (without having to anesthetize them). The tube was then lowered into the sample chamber of the instrument for approximately 2 minutes, the duration of the scan.

\section{Intraperitoneal glucose tolerance test (ipGTT)}

Mice were fasted for 12 hours and basal glucose was measured. Mice were then administered an i.p. bolus of glucose $(2.0 \mathrm{~g} / \mathrm{kg}$ body weight) and glycemia was monitored every 30 minutes for up to 120 minutes. Glycemia was measured with an Accu Check Active glucometer (Roche diagnostics, Mannheim, Germany).

\section{Intraperitoneal insulin tolerance test (ipITT)}

Mice were weighted and fasting blood glucose levels were measured. Mice were then administered an i.p. injection of insulin $(0.1 \mathrm{U} / \mathrm{mL}$; Humulin human insulin; Eli Lilly, São Paulo, Brazil) resulting in a dose of $0.5 \mathrm{U} / \mathrm{kg}$. Blood glucose was measured at 15, 30, 45, 60, and 120 min after injection.

\section{Biodistribution}

The mice were maintained under controlled temperature $\left(23^{\circ} \mathrm{C} \pm 2\right)$ with water and food ad libitum. No anesthetic was used. The labeled samples (3.7 $\mathrm{MBq} / 0.2 \mathrm{~mL}$ ) were administered by intraocular (retro-orbital) injection as described 
in table 1. After 24 hours of drug administration, the mice were sacrificed by asphyxiation $\left(\mathrm{CO}_{2}\right.$ chamber $)$ and then dissected and their lungs were removed, weighed and the radioactivity uptake counted in a gamma counter (Perkin Elmer). Results were expressed as percentage of injected dose per gram of tissue. The Institutional Review Board and the Animal Ethics Committee approved the study protocol.

Table 1: Distribution of number of animals ( $n$ ) used for the biodistribution study with radiolabeled nanoparticles (magnetic core mesoporous silica and polycaprolactone ethambutol) into the two groups: obese and nonobese (lean) mice.

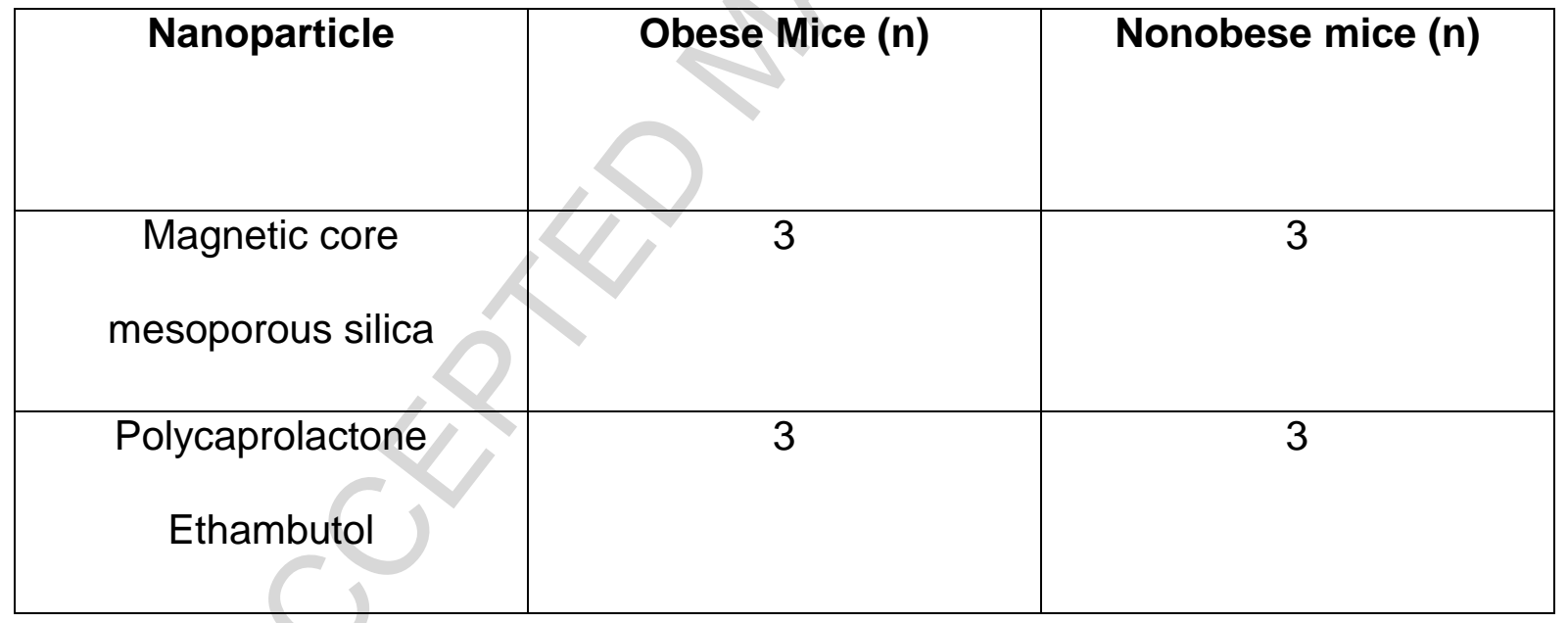

\section{Statistical Analysis}

The data were expressed as means standard error and analyzed by the twotailed unpaired Student's $t$ test. When appropriate, individual comparisons were subsequently tested with Bonferoni's $t$ test for unpaired values. Differences were 
considered statistically significant when $p<0.05$. The data were analyzed using GraphPad Prism version 5.00 for Windows (GraphPad Software, USA).

\section{RESULTS \& DISCUSSION}

\section{Magnetic Core Mesoporous Silica}

\section{Characterization of Magnetic Core MSNs}

The structure periodicity of the mesoporous material was confirmed by PXRD, which showed a sharp peak at the low-angle region for both as-made (S01) and calcined (S0-2) magnetic core MSNs (Figure 1). The slight shift of the peak to higher angles indicates a shrinkage of the silica matrix due to the condensation of silanol groups during the calcination process. PXRD analysis at high angles confirmed the presence of magnetic cores within the structure (see inset in Figure 1).

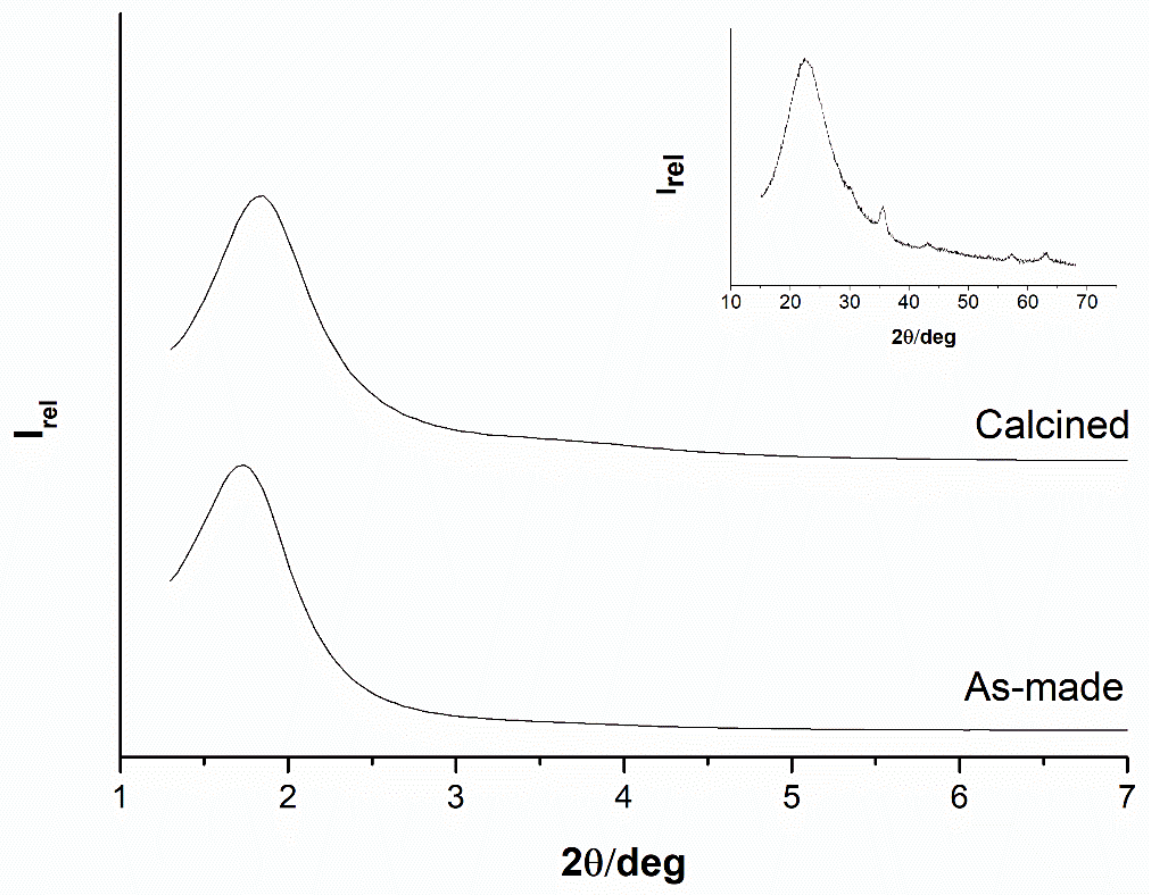


Figure 1.X-ray diffraction analysis of the magnetic core MSNs (S0-1) and calcined magnetic core MSNs (S0-2), showing the magnetite nanocrystals and the characteristic broad peak of amorphous silica.

The mesoporous structure of S0-2 magnetic core MSNs was also analysed by transmission electron microscopy and the size of the primary nanoparticles was determined by image analysis $(58.9 \pm 8.1 \mathrm{~nm}, n=100)$. The data was represented in a histogram, which shows the particle size distribution of the $\mathbf{S 0 - 2}$ nanoparticles (Figure 2).

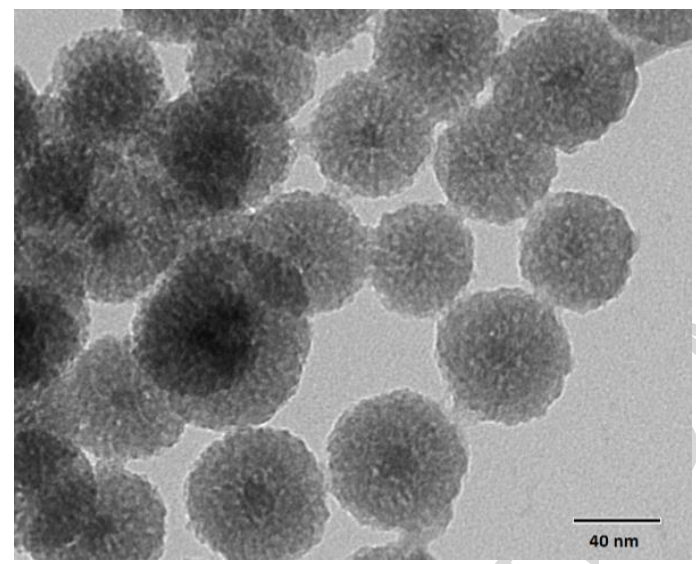

A

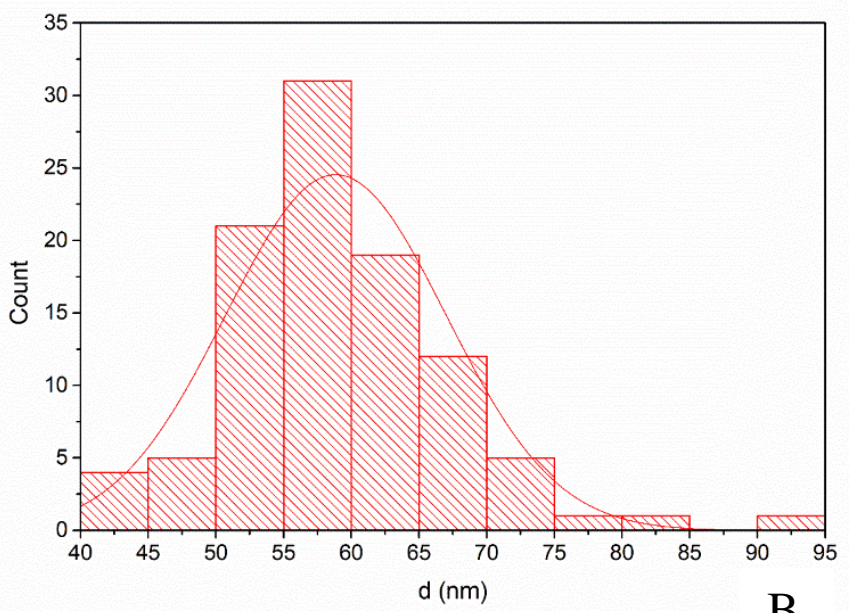

B

Figure 2. A: Transmission Electron Microscopy (TEM) images magnetic core mesoporous silicananoparticles. B: Size histogram and normal size distribution of magnetic core mesoporous silica nanoparticles, corroborating the size of 58nm.

The $\mathrm{N}_{2}$ adsorption-desorption isotherms of the magnetic core MSNs presented a typical type IV behaviour (Figure 3), characteristic of mesoporous materials. From the isotherm curve, a specific surface area of $872 \mathrm{~m}^{2} / \mathrm{g}$ was estimated along with a pore volume of $0.85 \mathrm{~cm}^{3} / \mathrm{g}$ and an average pore diameter of $3.15 \mathrm{~nm}$. 


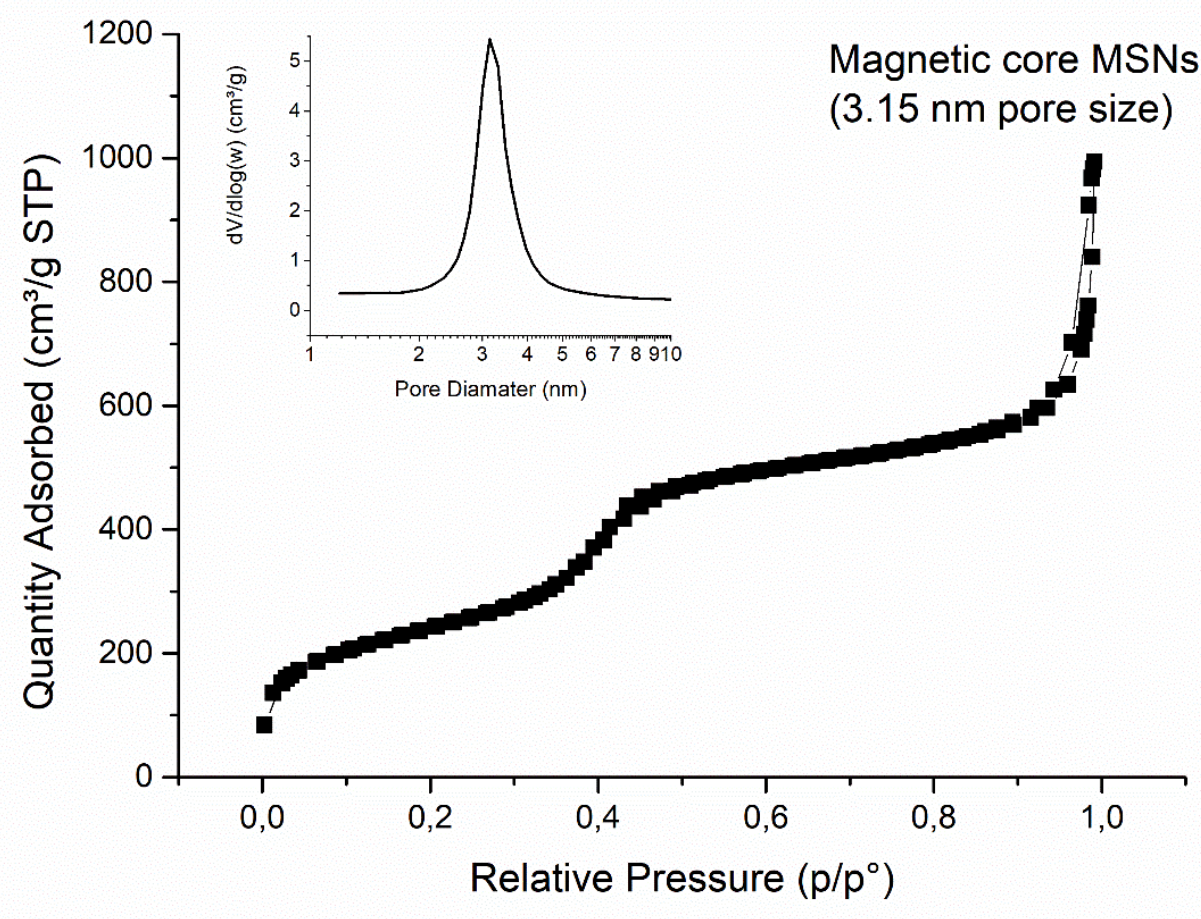

Figure 3. $\mathrm{N}_{2}$ adsorption-desorption analysis showing the pore size distribution of the magnetic core mesoporous silica nanoparticles, corroborating the pore size of $3.15 \mathrm{~nm}$.

\section{Ethambutol Polymeric Nanoparticle}

The results from SEM (figure 4) showed that nanoparticles size was about 280-300nm. A late SEM image demonstrated that nanoparticles may aggregate, forming a nanoparticle with a size no bigger than 500nm (figure 5). 


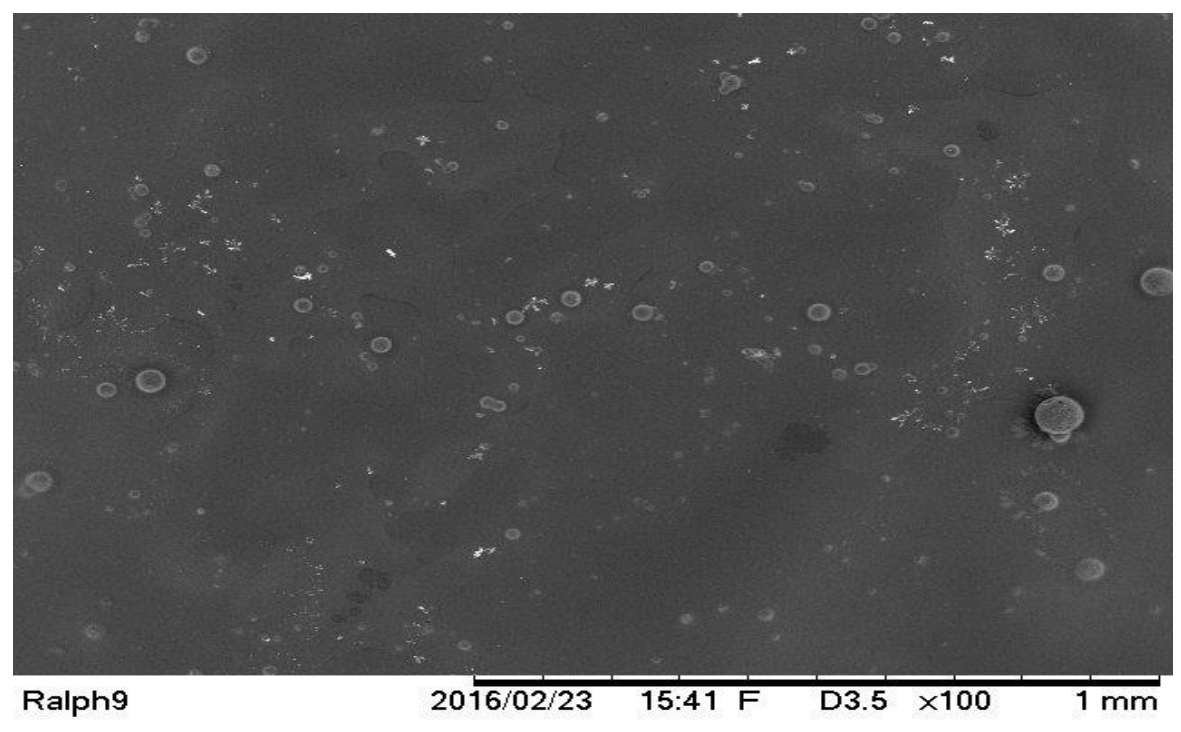

Figure 4-Scanning Electron Microscopy imaging, performed immediately after the production of the polymeric ethambutol nanoparticle showing nanoparticle with a range of size about $280-320 \mathrm{~nm}$.

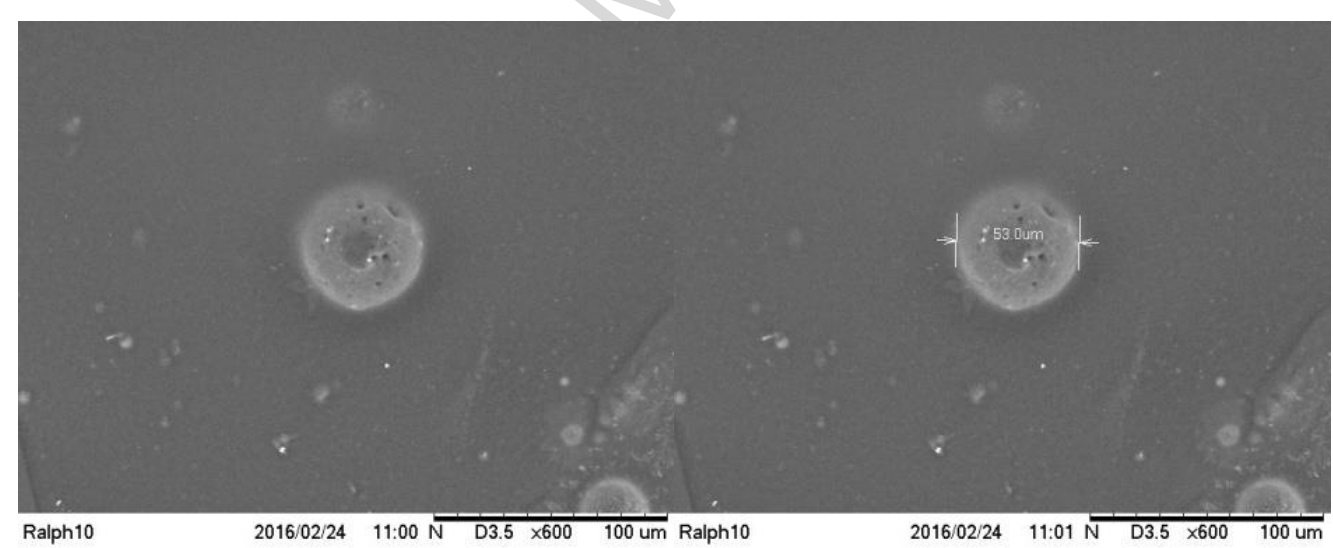

Figure 5: Scanning Electron Microscopy imaging, performed after 10 days of nanoparticles production, confirming the possibility of aggregation. 
Thus, considering the circumference volume (Cv) equation,

$$
C v=\pi r^{3}
$$

Where: Cv: circumference volume

П: constant pi

R: Radius of the circumference

The molar mass of PCl: $66.4268 \mathrm{~g} / \mathrm{mol}$. As also the medium average size of the ethambutol nanoparticle of $290 \mathrm{~nm}$, we have that the weight of one single ethambutol nanoparticle is about: $3,6 \times 10^{-15} \mathrm{~g}$.

\section{DLS Size Characterization}

Figure 6 shows the mean size and size distribution of the ethambutol nanoparticles. According to the distribution profile it is possible to infer that nanoparticles presented a monomodal size distribution, with a mean size of 270 $\mathrm{nm}$, corroborating the findings of SEM. The narrow peak suggests a homogeneous system with sizes near to the mean. According to Paranjpe and Müller-Goymann $(2014)^{[12]}$ particles smaller than $500 \mathrm{~nm}$ deposited in the alveolar region, it could sediment be retained in the bronchiolar region for a longer time when compared to nanoparticles, which could improve efficacy. 


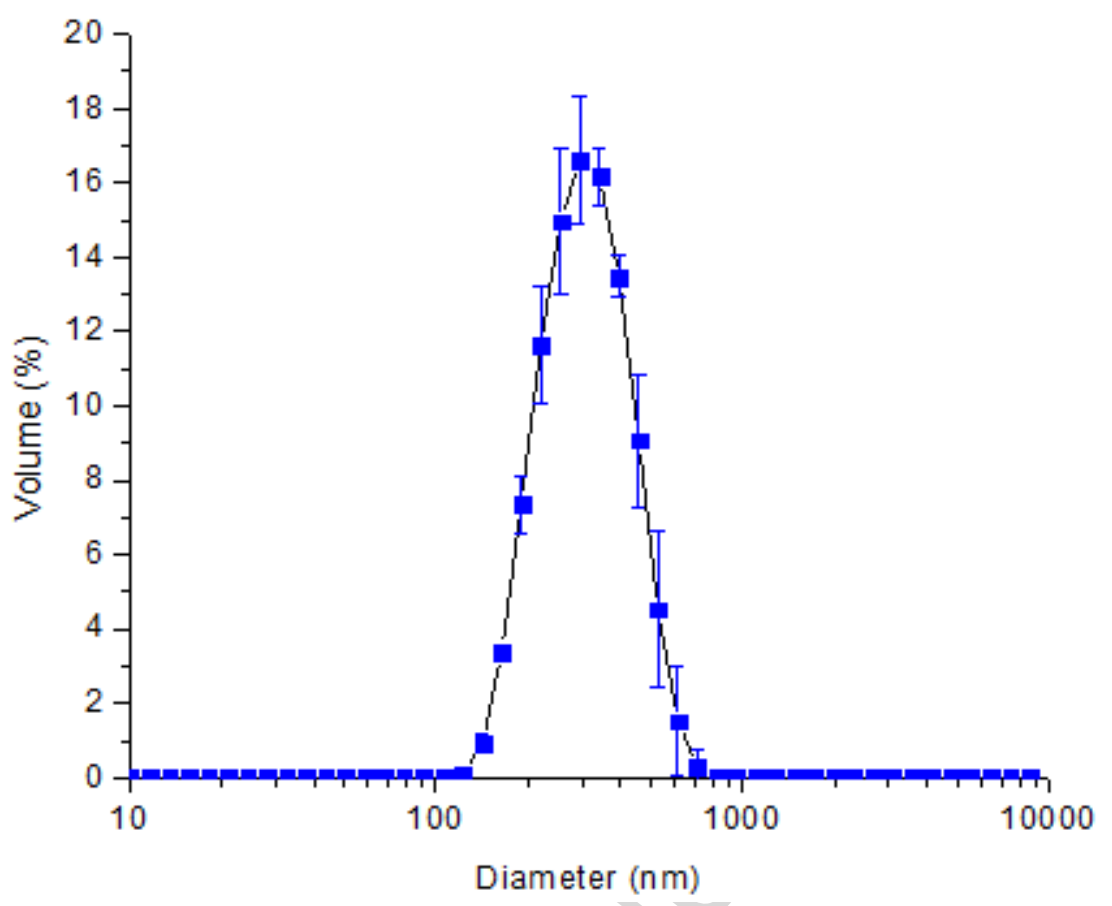

Figure 6 - Dynamic light scattering analysis (DLS) showing the mean size and size distribution of the polycaprolactoneethambutol nanoparticles, corroborating a monomodal size distribution, with a mean size of $270 \mathrm{~nm}$.

\section{Labeling with $99 \mathrm{mTc}$}

The magnetic core mesoporous silica nanoparticles were successfully labeled with $99 \mathrm{mTc}$, showing an average of labeling efficacy over $98 \%$. A similar result was found for the polymeric ethambutol nanoparticle which had a labeling efficacy of $99 \%$

\section{Quality Control}

The stability of the labeling process from the ethambutol polymeric nanoparticles and magnetic core mesoporous silica nanoparticles with the $99 \mathrm{mTc}$ were checked and the values are expressed in table 2 and 3. 
Table 2: Percentage of labeled ethambutol polymeric nanoparticles with ${ }^{99 \mathrm{~m}}$ Tcobserved over time (4 hours).

\begin{tabular}{|c|c|}
\hline Time $(\mathbf{h})$ & Labeling (\%) \\
\hline 0 & $99,52 \pm 1,2$ \\
\hline 1 & $99.45 \pm 1,3$ \\
\hline 2 & $99,55 \pm 1,0$ \\
\hline 4 & $99,21 \pm 1,1$ \\
\hline
\end{tabular}

Table 3: Percentage of labeled Magnetic Core Mesoporous Silica Nanoparticles with ${ }^{99 \mathrm{~m}} \mathrm{Tc}$ observed over time (4 hours).

\begin{tabular}{|l|l|}
\hline Time (h) & $\begin{array}{l}\text { Labeling (\%) Magnetic Core Mesoporous Silica } \\
\text { Nanoparticles }\end{array}$ \\
\hline 0 & $99.6 \pm 0.7 \%$ \\
\hline 1 & $98.8 \pm 0.5 \%$ \\
\hline 2 & $99.3 \pm 1.0 \%$ \\
\hline 4 & $98.0 \pm 0.8 \%$ \\
\hline
\end{tabular}

\section{Animals and high fat diet (HFD) protocol}

As observed by the body composition analysis in figures (7A, 7B and 7C), animals reached the obesity state that is characterized by increased body mass, with an increase in adipose mass and a decrease in lean mass and a marked 
reduction in glucose uptake, that has been confirmed by the ipGTT corroborating the changes in insulin and glucose tolerance (figure $8 \mathrm{~A}$ and $8 \mathrm{~B}$ )
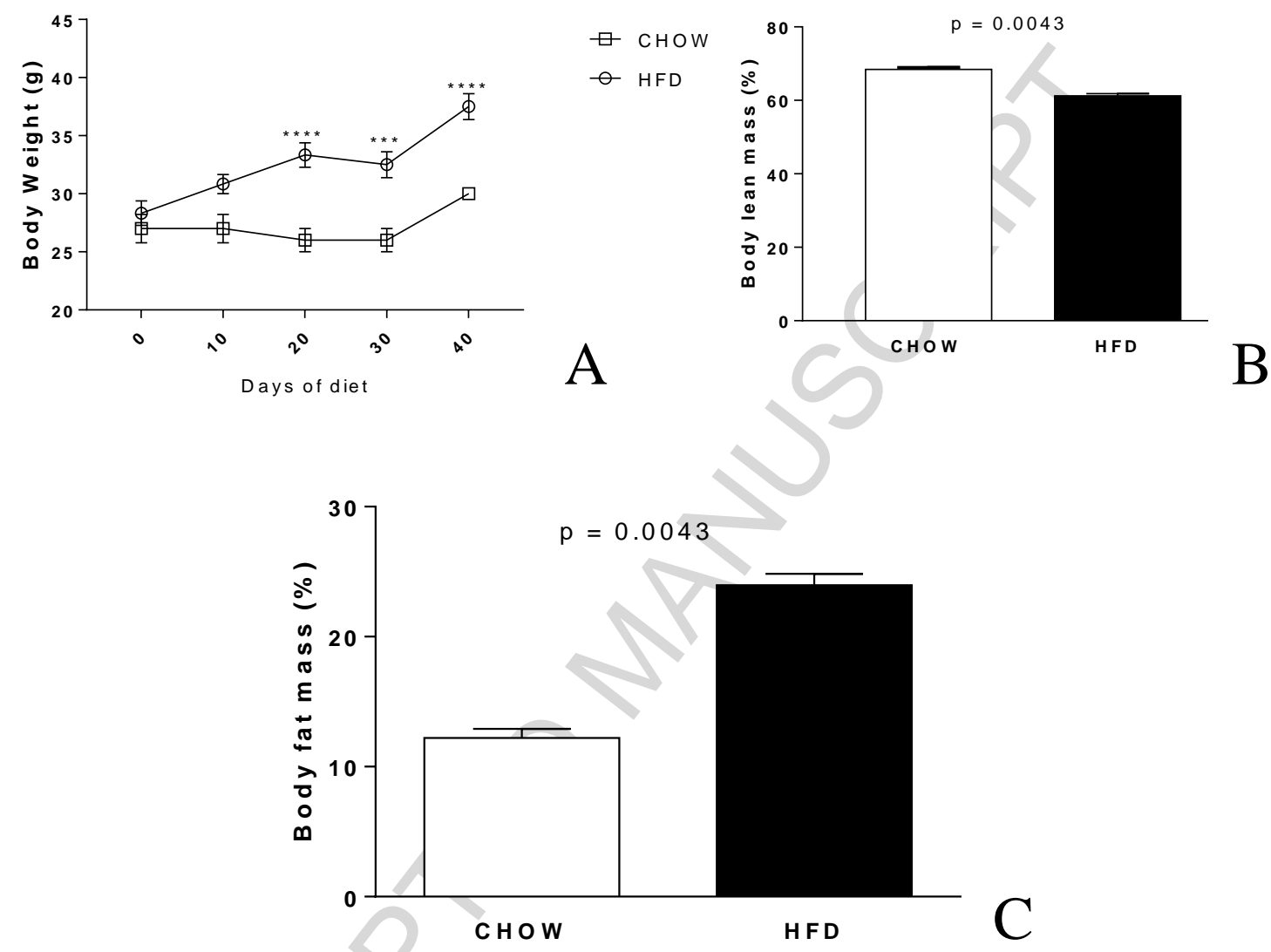

Figure 7: Body composition analysis with both groups under study (obese e nonobese) showing the alteration that all the animals reached in the obese group, as high increase in the body mass $(A)$, decrease in the lean mass $(B)$ and increase in fat mass (C). The results are shown as the mean \pm SE calculated from 3 different animals ${ }^{*} p<0.05$ and ${ }^{* *} p<0.001$ when compared to nonobese mice. 

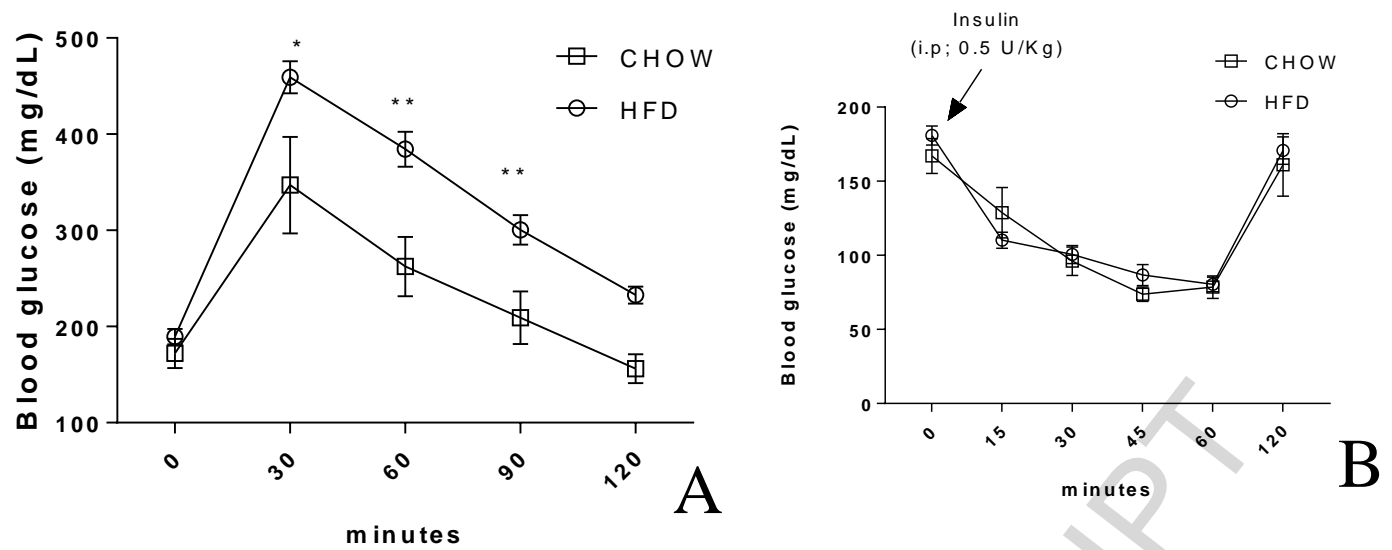

Figure 8:Comparison of Intraperitoneal insulin tolerance test (ipITT) (A) and intraperitoneal glucose tolerance test (ipGTT) (B) in both groups (obese and nonobese) shows the increase on insulin tolerance in the obese group with no difference on glucose tolerance, corroborating the obesity state of the obese group. 


\section{Biodistribution}

To address the interference of obesity on the biodistribution of polymeric nanoparticles (figure 9) and magnetic core mesoporous silica (figure 10), particles were injected (i.o.) in different groups of obese and non-obese mice. The distribution in the liver and spleen of obese and nonobese mice of the polymeric nanoparticles $24 \mathrm{~h}$ after its administrationis shown in Table 4.

Data indicates that a statistical difference between the two groups were detected in the distribution of polymeric nanoparticles in liver/spleen $(\Sigma)$, obese animals showed an apparent lower uptaking capacity (78,5\%), compared to nonobese mice $(92,04 \%)$, considering the total nanoparticles administered. Nevertheless, call attention the fact that spleens and liver of obese mice accumulated less nanoparticles $(9,03 \%$ and $69,47 \%$ respectively) than nonobese (12,49\% and $79,55 \%$, respectively).

Table 4: Evaluation on the uptake of ethambutol polymeric nanoparticles in liver and spleeninto the two groups (obese and nonobese).

\begin{tabular}{|c|c|c|c|c|}
\hline \multirow{2}{*}{} & \multicolumn{2}{|c|}{ \%uCi uptake } & \multicolumn{2}{c|}{$\%$} \\
\hline Organ & Obese & Nonobese & Obese & Nonobese \\
\hline Liver & $3,22( \pm 0,04)$ & $3,66( \pm 0,008)^{\star}$ & 69,47 & 79,55 \\
\hline Spleen & $0,419( \pm 0,003)$ & $0,575( \pm 0,003)^{\star \star *}$ & 9,03 & 12,49 \\
\hline
\end{tabular}

The results are shown as the mean \pm SE calculated from 3 different animals. ${ }^{*} p<0.05$ and ${ }^{* *} p<0.001$ when compared to nonobese mice. 
Several studies on biodistribution of nanoparticles have shown that they can be highly uptaken(from $30 \%$ to $99 \%$ )by liver and spleen ${ }^{[13 ; 14]}$, two organs with an active mononuclear phagocyte system (MPS).This systemworks, particularly in spleen, lymphonodes and liver, as an immune network to remove foreign material and pathogens from the bloodstream ${ }^{[15-17]}$. In the liver, although Kupffer cells, have been consideredthe main responsible for phagocytic activity ${ }^{[18]}$,recent studies suggested that other cells in thehepatic inflammatory microenvironment should be considered for nanoparticlessequestration ${ }^{[17,19]}$.

Obesity has been characterized as a low-grade inflamed sub-acutestate, characterized by a chronic infiltration of macrophages in adipose tissue, which in turn mediates local and systemic inflammation and acts as a key contributor to insulin resistance ${ }^{[20]}$. Adipose tissue macrophagesare derived largely from circulating monocytes stimulated by inflammatory mediators released by the obese adipose tissue ${ }^{[21-23]}$, and may contribute, as a classical MPS organ, to nanoparticlesuptake by the obese adipose tissue.Furthermore, considering that in obese mice the abdominal region is more distended, this may cause an increase in vessel diameter, augmenting vessels fenestration and volume, consequently increasing the perfusion volume ${ }^{[24-27]}$. In agreement, as shown in Table 5, a higher uptake of nanoparticles by the epidydimal and abdominal fat tissue in obese mice than nonobese mice. 
Table 5: Evaluation on the uptake of ethambutol polymeric nanoparticles by the fat tissue in obese and nonobese animals

\begin{tabular}{|c|c|c|}
\hline & \multicolumn{2}{|c|}{ \%uCi uptake } \\
\hline Organ & Obese & Nonobese \\
\hline Epididymal fat & $0,01( \pm 0,0004)$ & $0,003( \pm 0,00006)^{\star}$ \\
\hline Abdominal fat & $0,036( \pm 0,0008)$ & $0,0083( \pm 0,00005)^{\star * *}$ \\
\hline
\end{tabular}

The results are shown as the mean $\pm S E$ calculated from 3 different animals ${ }^{*} p<0.05$ and ${ }^{* *} p<0.001$ when compared to nonobese mice.

As can be observed in the fat tissue, occurred an increased ratio of 2.77 -fold $(0,0460 / 0,00136)$ higher uptake in obese when compared to nonobese (Table 5). Although the uptake by the adipose tissue respondedfor less than $2 \%$ of the total amount of nanoparticles injected in the animals, is important to emphasize that the inflamed condition in obesity may contribute to increase the uptake of nanoparticles by the obese adipose tissue.The obese state in our model, also contributes for an increased uptake by stomach and intestines (Figure 9), and fat accumulation in these organs justifies the results. Visceral adipositycaninducethe production of pro-inflammatory mediators and immune-cell infiltration, contributing to the low-grade systemic inflammation, resulting in macrophage accumulation/migration, insulin resistance and metabolic syndrome, and consequently high uptake of nanoparticles ${ }^{[32]}$. 
A discrete but higher uptake by pancreas was observed in obese mice(Figure 9). During obesity, the pancreatic functions are rather overwhelmed. This highly-activated state in obese mice is subsidized mainly by the accumulated peri-pancreaticadipose tissue, allowinga higher uptake by the organ ${ }^{[3,34]}$.,

The metabolic alterations in obesity can dramaticallyaffect the cardiovascular and pulmonary system. Obese individuals often present distension of the thoracic-abdominal region that can lead to limited diaphragm mobility and rib movement. Nonetheless, the excess of adipose tissue may also lead to lung hypodevelopment ${ }^{[35]}$, with alterations inbronchial responsiveness, and risk of asthma. Because of that, obese individuals tend to present higher respiratory rates and lower tidal volume ${ }^{[36,37]}$. All these factorsmayexplain the higher uptake of nanoparticles by lungs (right and left) ofobesemice, when compared tononobese.

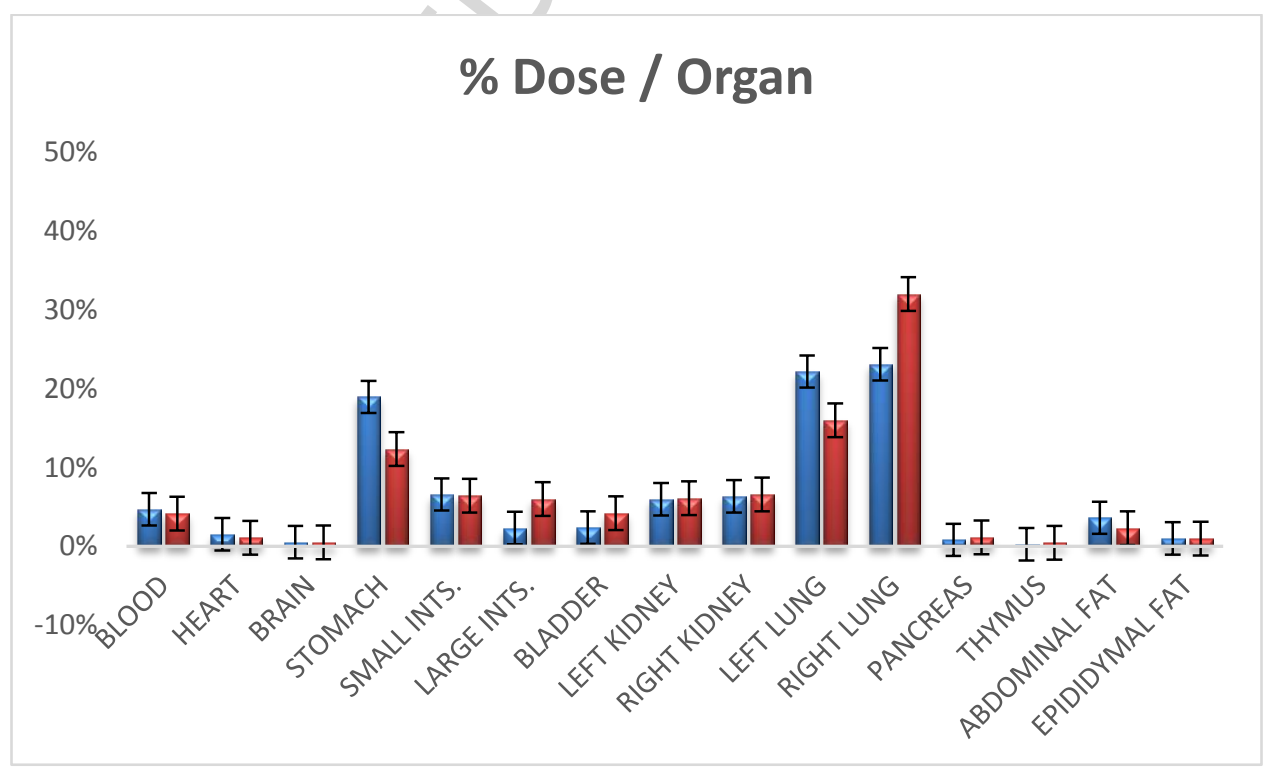

Figure 9: Biodistribution of $99 \mathrm{mTc}$ labeled ethambutol polymeric nanoparticles in obese (blue) and nonobese (red) mice. Due the high uptake of the $99 \mathrm{mTc}$ labeled 
ethambutol polymeric nanoparticles in liver and spleen these both data has been removed in order to better understand the behavior in the other organs.

The biodistribution of the magnetic core mesoporous silica, have shown to be very much alike to that of the polymeric nanoparticle of ethambutol, and there was no great change between obese and nonobese mice in the total body distribution (figure 10).

The results from biodistribution of magnetic core mesoporous silica nanoparticles showed no difference in uptake by the liver in both cases: obese and nonobese mice. On the other hand a great difference of over 33-fold higher uptake in spleen by obese mice was observed, as demonstrated in table 6 :

Table 6: Evaluation on the uptake of magnetic core mesoporous silica nanoparticles by the liver and spleen in obese and nonobese mice.

\begin{tabular}{|c|c|c|c|c|}
\hline & \multicolumn{2}{|c|}{$\%$} & \multicolumn{2}{c|}{$\%$} \\
\hline Organ & Obese & Nonobese & Obese & Nonobese \\
\hline Liver & $0,12( \pm 0,006)$ & $0,01( \pm 0,0003)^{\star}$ & 33,64 & 27,94 \\
\hline Spleen & $0,099( \pm 0,0002)^{\star}$ & $0,003( \pm 0,00002)^{\star \star *}$ & 26,94 & 8,31 \\
\hline
\end{tabular}

The results are shown as the mean $\pm S E$ calculated from 3 different animals ${ }^{*} \mathrm{p}<0.05$ and ${ }^{* *} \mathrm{p}<0.001$ when compared to nonobese mice.

The great difference of uptake in spleen between obese and nonobese mice in the case of magnetic core mesoporous silica can be explained by the fact that during 
obesity a splenomegaly via sinusoidal dilatation and intra-cellular or intercellular deposits is observed. The splenomegaly, increases the discontinuous gaps at endothelium, which lines the sinusoidal walls spleen, allowing the passive entrapment of foreign particulates ${ }^{[38,39]}$, especially the ones with small size, as the magnetic core mesoporous silica $(58 \mathrm{~nm})$. For that reason, a higher uptake of magnetic core mesoporous silica nanoparticles in spleen was observed in obese mice than in nonobese.

An important fact that our data showed is regarding the facilitated interaction between mesoporous silica and macrophages. According to the literature, due the large surface area of the mesoporous silica nanoparticles, the interaction between macrophages and magnetic core mesoporous silica, should be facilitate, leading to their rapid recognition by the MPS, and fast clearance by RES, especially in obese mice, which the MPS is highly activated ${ }^{[40,41]}$. In contrast, polymeric agents(as the polycaprolactone, used in the ethambutol nanoparticles) tend to create a steric hindrance and repulsion effect of polymeric chains against blood proteins and macrophages ${ }^{[42]}$, resulting in a "protective" effect making this system less prone to the action of the MPS. In our study we found exactly the opposite of the literature. We had a high recognition by the MPS of polymeric nanoparticles $\left(\sum 78,5 \%\right.$ and $\left.\sum 92,04 \%\right)$, respectively obese and nonobese mice. While the magnetic core mesoporous silica nanoparticles showed ahalved uptake by the MPS $(\Sigma 60,58 \%$ and $\left.\sum 36,25 \%\right)$ obese and nonobese mice, respectively. The most accepted explanation is due the size, where bigger nanoparticles are more likely to be recognized by the MPS ${ }^{[43-45]}$. Then, indifferent to surface features, size outweighs recognition by the MPS. 


\section{\% Dose / Organ}

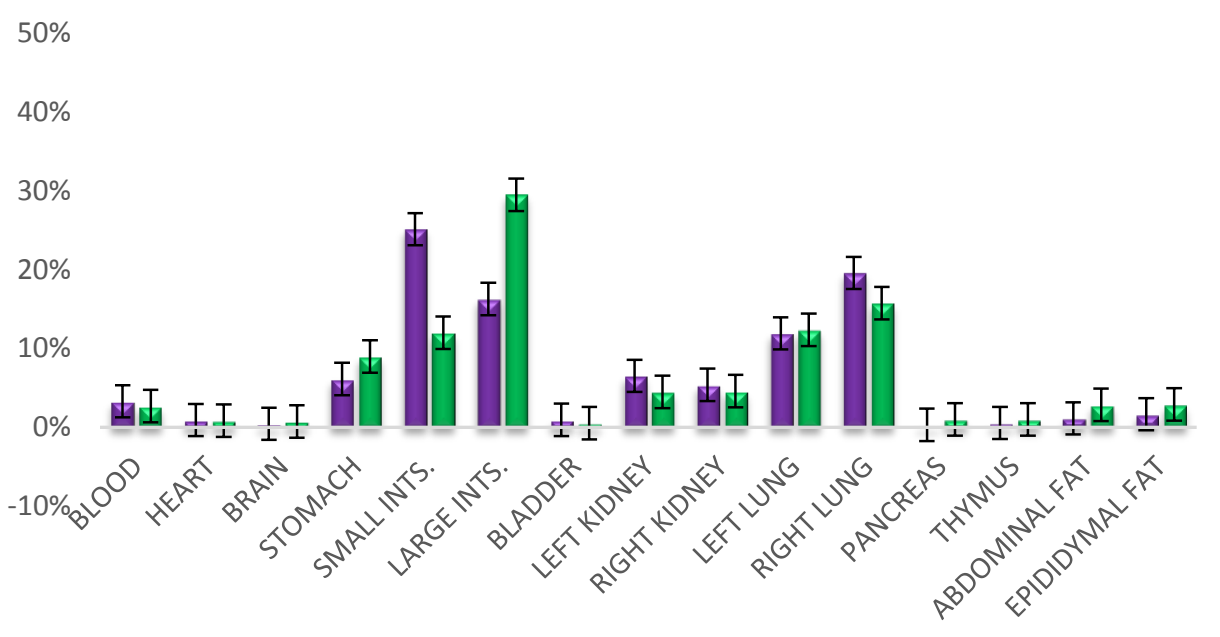

Figure 10: Biodistribution of $99 \mathrm{mTc}$ labeled magnetic core mesoporous silica nanoparticles in obese (purple) and nonobese (green) mice. Due the high uptake of the $99 \mathrm{mTc}$ labeled ethambutol polymeric nanoparticles in liver and spleen these both data has been removed in order to better understand the behavior in the other organs

Table 7: Evaluation on the uptake of magnetic core mesoporous silica nanoparticle by the fat tissue in obese and nonobese animals.

\begin{tabular}{|c|c|c|}
\hline Organ & \%uCi uptake Obese & \%uCi uptake Nonobese \\
\hline Epididymal fat & $0,0024( \pm 0,00006)$ & $0,00082( \pm 0,00004)^{\star \star \star}$ \\
\hline Abdominal fat & $0,0016( \pm 0,00004)$ & $0,00082( \pm 0,00001)^{\star}$ \\
\hline
\end{tabular}


The results are shown as the mean \pm SE calculated from 3 different animals ${ }^{*} p<0.05$ and ${ }^{* *} p<0.001$ when compared to nonobese mice.

It is important to notice that a higher uptake in fat tissue was observed for the magnetic core mesoporous silica, with a ratio of 2.44-fold $(0,004 \mathrm{uCi} / 0,00164 \mathrm{uCi})$ higher uptake in obese related to nonobese (table 7$)$. Almost the same ratio found in the polymeric nanoparticles. This data confirm the participation of the MPS in the whole of biodistribution of nanoparticles.

\section{CONCLUSION}

Our data demonstrated that obesity can interfere in the biodistribution of nanoparticles, with participation of the fat tissue. The exactly mechanism involved and responsible for these changes must be elucidated in order to promote the safety use of nanoparticles in different population strata.

Also, our findings suggest that, probably, due the low-grade inflammatory state, leading to a metabolic syndrome, observed in obesity, a critical paradigm shift can be observed. In general, the literature subsidizes that very small $(15<\mathrm{nm})$ nanoparticles are filtered by the kidney; nanoparticleslarger than $15 \mathrm{~nm}$ and smaller than $200 \mathrm{~nm}$ are captured by Kupffer cells and splenic marginal zone macrophages, whereas particles larger than $200 \mathrm{~nm}$ are retained in the red pulp of the spleen. Our data showed that in obesity the opposite occurs. We had bigger nanoparticles $(280 \mathrm{~nm})$ higher uptaken by the liver (Kupffer cells), whereas smaller nanoparticles $(58 \mathrm{~nm})$ higher uptaken by the spleen. 
Nonetheless, our data suggest that regardless the surface characteristics, the nanoparticles size seems to have a predominant effect, especially regarding the spleen uptake, which under specific conditions (splenomegaly) tends to be more permeable to smaller nanoparticles.

Other studies using different nanoparticles such as Au-nanoparticles, PLAnanoparticle, SBA-15 mesoporous silica nanoparticles and Spions, should be performed in order to corroborate our findings and ensure the interference of obesity in the processes related to normal biodistribution of nanoparticles.

\section{Transparency declarations section}

The authors state that do not have any conflicts of interest

\section{Funding}

The authors would like to thank the National Scientific and Technological Research Council (CNPQ) and the Rio de Janeiro State Research Foundation (FAPERJ) for funding.Authors also gratefully acknowledge the financial support from the Ministerio de Economía y Competitividad (Project MAT2012-38429-C04-01) and the GeneralitatValenciana (project PROMETEO/2009/016) for support. 


\section{REFERENCES}

[1] WHO staff work side by side with governments and other partners to ensure the highest attainable level of health for all people, http://www.who.int/mediacentre/factsheets/fs311/en/,access in: 12/2015.

[2]M. J.Hanley, D. R. Abernethy, D. J. Greenblatt,ClinPharmacokinet. 2010 ,49 , 71.

[3] CheymolG, ClinPharmacokinet. 1993, 25(2), 103.

[4] H. Mulla, T. N. Johnson, Arch Dis Child EducPract Ed. 2010, 95(4), 112.

[5] C. Ghobadi, T. N. Johnson, M. Aarabi, L. M. Almond, A. C. Allabi, K. RowlandYeo, M. Jamei, A. Rostami-Hodjegan, ClinPharmacokinet. 2011, 50(12), 809.

[6]C.A.J. Knibbe, M. J.E. Brill,A. van Rongen, J.Diepstraten, P. H. van der Graaf, M.Danhof,Annu. Rev. Pharmacol. Toxicol. 2015,55, 28.1.

[7] The mission of StatNano is to monitor the status of nanotechnology development and policies in the world, http://statnano.com/, accessed: 01/2018.

[8] O. V.Salata,JNanobiotechnology, 2004, 2, 3.

[9] C.F. Araujo-Lima, R.J.M. Nunes, R.M. Carpes, C.A.F. Aiub, I. Felzenszwalb, BioMed Res. 2017. 
[10] L. Pascual, F. Sancenón, R.Martínez-Máñez, T. C. Barja-Fidalgo, S. V. da

Silva, A. J. Sousa-Batista, C. Cerqueira-Coutinho,R.SantosOliveira,MicroporousandMesoporousMaterials, 2017, 239, 426.

[11]T. G. Rosa, S. N. Dos Santos, T. de Jesus Andreoli Pinto, D. D. M. Ghisleni, T. C. Barja-Fidalgo, E. Ricci-Junior, M. Al-Qahtani, J. Kozempel, E. S. Bernardes, R. Santos-Oliveira, Pharm Res. 2017.

[12]M. Paranjpe, C. C. Müller-Goymann, Int J Mol Sci. 2014, 8;15(4), 5852.

[13] Y.-N. Zhang, W. Poon, A. J. Tavares, I. D. McGilvray, W. C.W. Chan, Journal of Controlled Release, 2016, 240, 332.

[14] X. Sun, X. Yan, O. Jacobson, W. Sun, Z. Wang, X. Tong, Y. Xia, D. Ling, X.Chen,Theranostics, 2017, 7(2), 319.

[15] K. M. Tsoi, S. A. MacParland, X.-Z. Ma, V. N. Spetzler, J.Echeverri, B. Ouyang, S. M. Fadel, E. A. Sykes, N. Goldaracena, J. M. Kaths, J. B. Conneely, B. A. Alman, M.Selzner, M. A. Ostrowski, O. A. Adeyi, A.Zilman, I. D. McGilvray, W. C. W. Chan

Nature Materials, 2016, 15, 1212.

[16]Y. Liu, Z. Wang, Y. Liu, G. Zhu, O. Jacobson,X. Fu, R. Bai, X. Lin, N. Lu, X. Yang, W. Fan, J. Song, Z. Wang, G. Yu, F. Zhang, H. Kalish, G. Niu, Z. Nie, X. Chen, ACS Nano, 2017, 24;11(10), 10539. 
[17] S. A. MacParland, K. M. Tsoi, B. Ouyang, X. Z. Ma, J. Manuel, A. Fawaz, M. A. Ostrowski, B. A. Alman, A. Zilman, W. C. Chan, I. D. McGilvray,ACS Nano, 2017, 28;11(3), 2428.

[18]S.F.dos Santos, S.R.R. Reis, L.P. Pires,E. Helal-Neto, F. Sancenóncde, T.C. Barja-Fidalgo, R.M. Mattos, L.E. Nasciutti, R. Martínez-Máñez, R. SantosOliveira,Microporous and Mesoporous Materials, 2017, 251, 181.

[19] E. Samuelsson, H. Shen, E. Blanco, M. Ferrari, J. Wolfram,ColloidsSurf.B.Biointerfaces, 2017,158, 356.

[20]A. Castoldi, C.N. de Souza, N.O.S, Camara, P.M. Moraes-Vieira, Front Immunol. 2015; 6: 637.

[21]M. Renovato-Martins, M.E. Matheus, J.A. Moraes, S.V.da Silva, M. Citelli dos Reis, A.A.de Souza, C.C. da Silva, E. Bouskela, C. Barja-Fidalgo, BiochimBiophysActa. 2017 1863(1):139-151.

[22]Y. Bai, Q. Sun, Obes Rev. 2015, 16(2), 127.

[23] A. Booth, A. Magnuson, J.Fouts, M.T. Foster, HormMolBiolClin Invest 2016; 26(1): $25-42$

[24]P. A. Stapleton, M. E. James, A. G. Goodwill, J. C. Frisbee, Pathophysiology, 2008, 15(2), 79.

[25]M. Barton, O.Baretella, M. R.Meyer,Br J Pharmacol. 2012, 165(3), 591.

[26] L. Wang, L. Djousse, Y. Song, A. O. Akinkuolie, C. Matsumoto, J. E. Manson, J. M. Gaziano, H. D. Sesso,JObes. 2017, 2017, 3521649. 
[27]I.Broom,Br J Diabetes VascDis. 2006, 6, 58.

[28]N. J. Talley, S. Howell, R. Poulton, Am J Gastroenterol. 2004, 99(9), 1807.

[29]M.A.Mushref, S. Srinivasan, Ann Transl Med. 2013, 1(2), 14.

[30]A. Acosta, M. Camilleri, Ann N Y Acad Sci. 2014, 1311, 42.

[31]M. M. Wolfe, M.O. Boylan, J ClinGastroenterol. 2014, 48(10), 817.

[32]L. I. Kredel, B.Siegmund,FrontImmunol. 2014, 5, 462.

[33]S.Navina, V. P. Singh, Pancreapedia: Exocrine Pancreas Knowledge Base, 2015, Version 1.0, June 13.

[34]N. J. Zyromski,Pancreapedia: Exocrine Pancreas Knowledge Base, 2015, Version 1.0, June 27.

[35]L. C. Melo, M. A. Mendonça da Silva, A.C.N.Calles, Einstein (Sao Paulo), 2014, 12(1), 120.

[36]S. W. Littleton, Respirology, 2012, 17(1), 43.

[37]C. M. Salome, G. G. King, N. Berend, J ApplPhysiol (1985), 2010, 108(1), 206.

[38]B. Z. Altunkaynak, E. Ozbek, M. E. Altunkaynak, Saudi Med J. 2007, 28(3), 353.

[39]T. Yu, D. Hubbard, A. Ray, H.Ghandeharia, J Control Release, 2012, 163(1), 46. 
[40]F. Chen, H. Hong, S. Shi, S.Goel, H. F. Valdovinos, R. Hernandez, C. P. Theuer, T. E. Barnhart, W.Caia, Sci Rep.2014, 4, 5080.

[41]J.Hoppstädter, M.Seif, A.Dembek, C.Cavelius, H.Huwer, A.Kraegeloh,A. K. Kiemer, Front Pharmacol. 2015, 6, 55.

[42]M. Vallet-Regí, M. M. García, M. Colilla, Biomedical Applications of Mesoporous Ceramics:Drug Delivery, Smart Materials and Bone Tissue Engineering, CRC Press, Boca Raton, FI, USA, 2012, page 114.

[43]H. H. Gustafson, D. Holt-Casper, D. W. Grainger, H.Ghandehari, Nano Today, 2015, 10(4), 487.

[44] L.Shang,K.Nienhaus, G.U.Nienhaus, J Nanobiotechnology, 2014, 12, 5.

[45]E. Blanco, H. Shen, M. Ferrari, Nat Biotechnol.2015, 33(9), 941. 